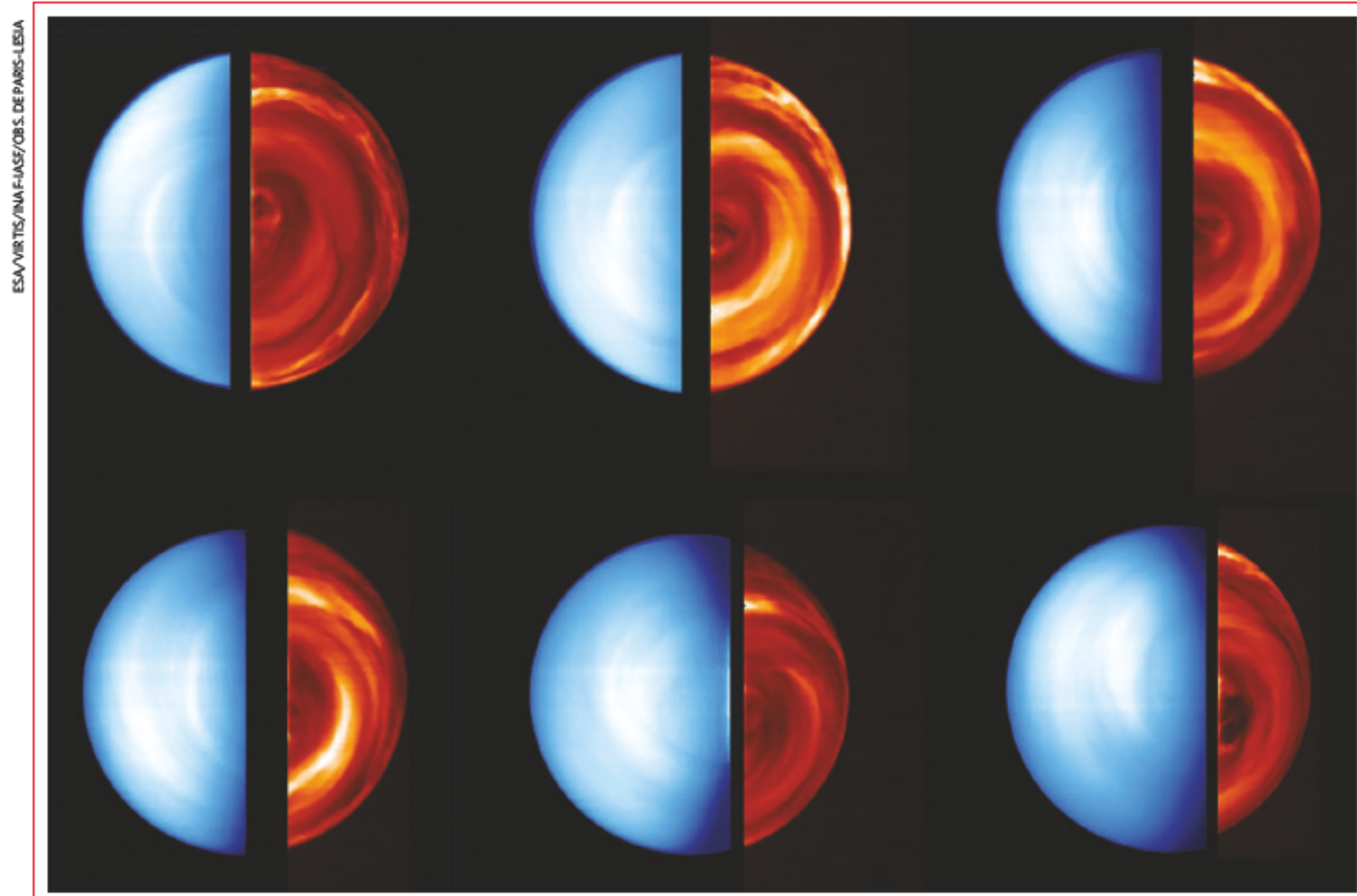

\title{
SNAPSHOT
}

\section{Venus by day and night}

These orbs of blue and red are the planet Venus, as seen by the European spacecraft Venus Express during its cruise into orbit. The composite images are among the first data transmitted from the craft, whose initial results will be discussed ata meeting of the Scientific Assembly of the Committee on Space Research (COSPAR), which convenes on 16 July in Beijing.

The gauzy blue to the left is the planet's dayside, imaged with ultraviolet light; it is bright with reflected sunlight. Scientists aren't sure what causes the white stripes - maybe some kind of aerosol particle is absorbing the ultraviolet light, says Hảkan Svedhem, Venus Express project scientist at the EuropeanSpace Agency (ESA). The angry red swirls to the right are clouds deep in the venusian atmosphere on the planet's night side. They are seen by infrared light, the only type of radiation that makes itout through the dense atmosphere. The clouds appear as dark shadows in the infrared glow of the planet's hot surface.

Unlike Earth's billowing water clouds, the clouds on Venus are made of sulphuric acid. They float in an atmosphere that is mainly carbon dioxide, and are dragged into a spiralling pattern by fierce, westward winds that tear around the planetat hundreds of metres per second. Here, we view the planet from one end, with the clouds circling the south pole.

The sequence of images was captured by the ultraviolet/visible/ near-infrared spectrometer(VIRTS) on Venus Express between 12and 19 April, from distances of between 190,000 and 315,000 kilometres while the spacecraft moved along a long ellipse around the planet.

Venus Express, which took just five months to make the journey from Earthto its neighbour, has since moved intoa closer, final orbit.

The science instruments were switched offduring the craft's orbital manoeuvres, butsince 4 June, data from its cameras, spectrometers and analysers have been streaming back to ESA's deep-space antenna atCebreros, justoutside Madrid, Spain. Earlier missions to Venus, by NASA's Mariner probes and the Soviet Union's Venera programme among others, have revealed atmospheric
STILLTHE FASTEST

COMPUTER ON EARTH IBM's BlueGene/L supercomputer grabs first place again in TOP 500 list. www.nat ure.com/news

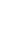

